Buletin Ilmiah Math. Stat. dan Terapannya (Bimaster)

Volume 08 No.3 (2019), hal 599-606

\title{
KONTROL OPTIMAL PADA MODEL EPIDEMI TIPE SEIT DENGAN METODE PRINSIP MINIMUM PONTRYAGIN
}

\author{
Laila Tul Machfiroh, Helmi, Yudhi
}

\begin{abstract}
INTISARI
Model epidemi pada penelitian ini dibagi menjadi empat sub-populasi, yaitu sub-populasi susceptible $(S)$, sub-populasi exposed (E), sub-populasi infective (I), dan sub-populasi treatment $(T)$. Dari keempat subpopulasi tersebut kemudian dibentuk model epidemi tipe SEIT. Model yang terbentuk kemudian diberikan kontrol, yaitu kontrol pengobatan untuk sub-populasi exposed $\left(u_{1}\right)$ dan sub-populasi infective $\left(u_{2}\right)$. Pemberian kontrol bertujuan untuk meminimalkan jumlah individu exposed dan individu infective. Prinsip minimum Pontryagin merupakan salah satu metode untuk mendapatkan kontrol yang optimal dari suatu sistem. Hasil penelitian ini menunjukkan keefektifan kontrol dalam mengendalikan penyebaran suatu penyakit sehingga dapat mengurangi jumlah individu infective dan meminimumkan biaya pengobatan.
\end{abstract}

Kata kunci : model epidemi tipe SEIT, kontrol optimal, prinsip minimum Pontryagin

\section{PENDAHULUAN}

Permasalahan yang terjadi dalam dunia nyata dapat diterjemahkan ke dalam bahasa matematika. Dengan menerjemahkan permasalahan ke dalam bahasa matematika akan didapatkan model matematika, yaitu hasil perumusan yang menggambarkan permasalahan yang akan dicari solusinya[1].

Model matematika mempunyai peranan penting untuk menganalisis penyebaran dan mengontrol suatu penyakit menular. Salah satu model matematika epidemi untuk menganalisis penyebaran penyakit diantaranya adalah SIR. Pada model SIR populasi dibagi menjadi tiga sub-populasi yakni sub-populasi individu yang rentan penyakit (susceptible), sub-populasi individu yang terinfeksi (infected), dan subpopulasi individu yang telah sembuh dan kebal dari penyakit (recovered).

Beberapa penyakit menular memiliki periode exposed. Periode exposed atau disebut juga periode laten adalah masa bersembunyinya penyakit dalam tubuh ketika sistem kekebalan tubuh dalam kondisi baik [2]. Tingkat kejadian infeksi nonlinier disebut juga tingkat kejadian infeksi tersaturasi. Tingkat kejadian infeksi menyatakan banyaknya kasus infeksi baru akibat interaksi antara individu rentan dengan individu terinfeksi [3]. Contoh penyakit dengan tingkat kejadian tersaturasi adalah penyakit campak, TBC, dan flu [4].

Penyebaran penyakit dapat dikontrol dengan pemberian obat pada individu terinfeksi. Oleh karena itu, pengobatan perlu dilakukan sebagai salah satu upaya untuk mencegah penyebaran penyakit menular. Pemberian obat pada model epidemi memunculkan sub-populasi baru yaitu sub-populasi treatment. Sub-populasi treatment adalah sekumpulan individu yang telah diberi pengobatan. Pengobatan sering kali terkendala oleh biaya, sehingga perlu ditentukan pengobatan yang optimal agar biaya yang dikeluarkan minimum namun pengobatan yang dilakukan tetap efektif dalam mengendalikan penyebaran penyakit [2].

Penelitian ini dimulai dengan membentuk model epidemi tipe SEIT (Susceptible Exposed Infective Treatment) dengan pemberian kontrol, mendapatkan kontrol yang optimal, dan efektifitas pengobatan dalam mengontrol jumlah individu infective. Model epidemi tipe SEIT pada penelitian ini diberikan beberapa batasan, yaitu individu yang menjadi objek penelitian ini adalah manusia, interaksi terjadi dalam suatu wilayah tertutup, individu exposed tidak memiliki kemampuan menularkan penyakit, dan individu yang diberi pengobatan dapat menjadi rentan dan terinfeksi kembali.

Langkah-langkah yang dilakukan dalam penelitian ini adalah menyusun asumsi-asumsi, mendefinisikan parameter yang digunakan pada model dan membentuk diagram transfer model epidemi 
tipe SEIT. Langkah selanjutnya adalah menentukan fungsi objektif $J$ dan membentuk fungsi Hamiltonian. Setelah dibentuk fungsi Hamiltonian kemudian diberi kontrol. Selanjutnya menentukan bentuk kontrol optimal $u^{*}(t)$ berdasarkan keadaan stasioner, menentukan persamaan state dan costate, menentukan kontrol optimal dari model yaitu dengan mensubstitusikan bentuk kontrol optimal $u^{*}(t)$ ke dalam persamaan state dan costate, dan menentukan kondisi batas. Pada penelitian ini kondisi awal dan kondisi batas telah ditentukan. Setelah menentukan kondisi batas, kemudian dilakukan simulasi numerik dan analisis hasil simulasi model epidemi tipe SEIT. Langkah terakhir yaitu interpretasi model epidemi tipe SEIT berdasarkan hasil yang diperoleh dari simulasi numerik.

\section{Teori Kontrol Optimal}

Tujuan utama dari permasalahan kontrol optimal yaitu untuk mencari nilai kontrol $u(t)$ yang disubstitusikan ke fungsi dinamik dan memenuhi kendala fisik atau konstrain. Pada waktu yang sama, dapat ditentukan nilai maksimum atau minimum yang memenuhi kriteria pada fungsi objektif. Formulasi masalah kontrol optimal terdiri dari deskripsi secara matematis suatu sistem atau model, menentukan fungsi objektif, dan kendala atau syarat batas yang berlaku, dengan tujuan untuk mencari nilai $u(t)$ yang dapat mengoptimalkan fungsi objektif [5]. Suatu sistem dinamik dengan $n$ persamaan adalah sebagai berikut,

$$
\dot{x}=f(x(t), u(t), t)
$$

dengan fungsi $f=\left(f_{1}, f_{2}, \ldots, f_{n}\right)$, variabel $x=\left(x_{1}, x_{2}, \ldots, x_{n}\right)$, kontrol keadaan pada waktu $t$ yaitu $u(t)$, keadaan awal pada waktu $t_{0}$ yaitu $x\left(t_{0}\right)=x_{0}$, dan keadaan akhir pada waktu $t_{f}$ yaitu $x\left(t_{f}\right)=x_{f}$. Dalam hal ini, masalah kontrol optimal adalah mencari kontrol optimal $u^{*}(t)$ yang memenuhi persamaan keadaan (state) dengan syarat nilai $J$ sebagai berikut,

$$
J=\bar{S}\left(x\left(t_{f}\right), t_{f}\right)+\int_{t_{0}}^{t_{f}} V(x(t), u(t), t) d t
$$

adalah minimum atau maksimum. Bentuk umum $J$ pada Persamaan (2) disebut fungsi tujuan bentuk Bolza dengan $\bar{S}$ bentuk Meyer dan $V$ adalah bentuk Lagrange, dengan kondisi sistem yaitu waktu akhir tetap atau bebas dan keadaan (state) akhir seluruhnya atau sebagian bebas atau tetap.

Pada penelitian ini akan dilakukan kontrol optimal terhadap model epidemi model tipe SEIT, dan metode kontrol optimal yang akan digunakan adalah Prinsip Minimum Pontryagin. Kontrol $u(t)$ yang digunakan adalah $u_{1}(t)$ yang dinotasikan untuk pengobatan pada individu exposed, dan $u_{2}(t)$ yang dinotasikan untuk pengobatan pada individu infective.

\section{Fungsi Objektif}

Tujuan penelitian ini adalah mendapatkan pengobatan optimal dengan meminimalkan jumlah populasi terinfeksi dan biaya pengobatan. Secara matematika, permasalahan ini adalah meminimalkan fungsi objektif berikut

$$
J\left(u_{1}, u_{2}\right)=\int_{t_{0}}^{t_{f}}\left(I(t)+\frac{C}{2} u_{1}^{2}(t)+\frac{D}{2} u_{2}^{2}(t)\right) d t
$$

dengan $C$, D adalah bobot pada biaya pengobatan, $t_{0}$ adalah waktu awal, dan $t_{f}$ adalah waktu akhir.

Kemudian akan diperoleh $u^{*}(t)$ sehingga berlaku

$$
J\left(u_{j}^{*}(t)\right)=\min \left\{J\left(u_{j}(t)\right): u_{j} \in \mathcal{U}\right\}
$$

dengan $\mathcal{U}=\left\{u_{j}(t) \mid 0 \leq u_{j} \leq 0.9, t \in\left[0, t_{f}\right], j=1,2\right\}[6]$. 


\section{Prinsip Minimum Pontryagin}

Prinsip Minimum Pontryagin digunakan untuk memproleh kontrol terbaik pada sistem dinamik dari keadaan awal hingga keadaan akhir dengan meminimumkan fungsi objektif. Langkah-langkah penyelesaian dari masalah kontrol optimal yang diformulasikan oleh Persamaan (1) dan (2) adalah sebagai berikut [5]

1. Membentuk fungsi Hamiltonian $(H)$

$$
H(x(t), u(t), \lambda(t), t)=V(x(t), u(t), \lambda(t), t)+\lambda^{\prime}(t) f(x(t), u(t), t)
$$

dengan $\lambda=\left(\lambda_{1}, \lambda_{2}, \ldots, \lambda_{n}\right)$ yang menyatakan penggali Lagrange dan tanda ' menyatakan suatu tranpose.

2. Meminimumkan $H$ terhadap $u(t)$ yaitu dengan cara:

$$
\frac{\partial H}{\partial u(t)}=0
$$

sehingga didapat kondisi stasioner $u^{*}(t)=h\left(x^{*}(t), \lambda^{*}(t), t\right)$

3. Dengan menggunakan $u^{*}(t)$ yang telah dihasilkan pada langkah 2 , akan didapatkan fungsi Hamiltonian baru yang optimal $\left(H^{*}(t)\right)$, yaitu:

$$
H^{*}\left(x^{*}(t), h\left(x^{*}(t), \lambda^{*}(t), t\right), \lambda^{*}(t), t\right)=H^{*}\left(x^{*}(t), \lambda^{*}(t), t\right)
$$

4. Selesaikan persamaan state dan costate

Mencari state dengan cara

$$
\dot{x}^{*}(t)=\left(\frac{\partial H}{\partial \lambda}\right)^{*}
$$

dan mencari costate dengan cara

$$
\dot{\lambda}^{*}(t)=-\left(\frac{\partial H}{\partial \lambda}\right)^{*}
$$

didapat kondisi batas yang diberikan oleh keadaan awal dan keadaan akhir yang disebut kondisi transversality, yaitu:

$$
\left(H^{*}+\frac{\overline{\partial S}}{\partial t}\right)_{t_{f}} \delta t_{f}+\left[\left(\frac{\overline{\partial S}}{\partial x}\right)-\lambda^{*}\right]_{t_{f}}^{T} \delta x_{f}=0
$$

dengan $\bar{S}$ adalah bentuk Meyer dari fungsi tujuan $J, H$ adalah persamaan Hamiltonian, $\delta$ menunjukkan variasi dan tanda $*$ menunjukkan keadaan saat variabel kontrolnya stasioner.

5. Substitusi $\dot{x}^{*}(t)$ dan $\dot{\lambda}^{*}(t)$ yang diperoleh pada langkah 4 ke persamaan $u^{*}(t)$ pada langkah 2 untuk mendapatkan kontrol yang optimal.

\section{Model Epidemi Tipe SEIT}

Populasi pada model dari epidemi tipe SEIT dibagi menjadi empat sub-populasi yaitu populasi susceptible, exposed, infective, dan treatment.

Berikut ini model epidemi tipe SEIT

$$
\begin{aligned}
& \dot{S}(t)=A-\theta S(t)-\frac{\beta S(t) I(t)}{1+\alpha I(t)}+\gamma I(t)+p T(t) \\
& \dot{E}(t)=\mu \frac{\beta S(t) I(t)}{1+\alpha I(t)}-\left(\theta+\varepsilon+u_{1}(t)\right) E(t) \\
& \dot{I}(t)=(1-\mu) \frac{\beta S(t) I(t)}{1+\alpha I(t)}+\varepsilon E(t)-\left(\gamma+\theta+\sigma+u_{2}(t)\right) I(t) \\
& \dot{T}(t)=u_{1}(t) E(t)+u_{2}(t) I(t)-(p+\theta) I(t)
\end{aligned}
$$

Pada Persamaan (5) menyatakan laju perubahan jumlah individu susceptible. Sub-populasi susceptible meningkat karena adanya individu baru yang lahir diasumsikan bahwa $A$ menyatakan jumlah kelahiran alami tiap waktu. Sub-populasi susceptible juga bertambah akibat adanya individu infective sembuh tanpa pengobatan tiap waktu $(\gamma I)$ dan individu treatment yang susceptible kembali tiap waktu 
$(p T)$. Sub-populasi susceptible berkurang karena kematian alami $(\theta S)$ dan adanya tingkat kejadian tersaturasi $\frac{\beta}{1+\alpha I}$ pada proses penularan. Pada saat jumlah individu infective sangat banyak atau mencapai titik jenuh maka laju infeksi semakin menurun. Populasi individu infective yang masuk ke dalam subpopulasi exposed sebesar $\mu$, dan yang masuk ke dalam sub-populasi infective sebesar $(1-\mu)$.

Pada Persamaan (6) menyatakan laju perubahan jumlah individu exposed. Sub-populasi exposed meningkat karena adanya interaksi antara individu susceptible terhadap individu infective sebesar $\mu$ dengan tingkat kejadian tersaturasi. Sub-populasi exposed berkurang karena adanya kematian alami tiap waktu $(\theta E)$ dan adanya individu exposed yang berubah menjadi infective tiap waktu $(\varepsilon E)$, serta adanya individu yang sembuh tiap waktu dengan pengobatan $u_{1} E$.

Pada Persamaan (7) menyatakan laju perubahan jumlah individu infective. Sub-populasi infective meningkat karena adanya interaksi antara individu susceptible terhadap individu infective sebesar $(1-\mu)$ dengan tingkat kejadian tersaturasi. Sub-populasi infective juga bertambah akibat adanya individu exposed yang berubah menjadi individu infective tiap waktu $(\varepsilon E)$. Sub-populasi infective berkurang akibat adanya individu infective sembuh tanpa pengobatan tiap waktu $(\gamma I)$. Sub-populasi infective juga berkurang karena kematian alami tiap waktu $(\theta S)$ dan kematian akibat penyakit tiap waktu $(\sigma I)$, serta adanya individu yang sembuh dengan pengobatan $\left(u_{2} I\right)$.

Pada Persamaan (8) menyatakan laju perubahan jumlah individu treatment. Sub-populasi treatment meningkat karena adanya individu exposed dan infective yang sembuh dengan pengobatan $\left(u_{1} E\right)$ dan $\left(u_{2} I\right)$. Sub-populasi treatment berkurang akibat adanya kematian alami tiap waktu $(\theta T)$, serta adanya individu treatment yang kembali menjadi susceptible tiap waktu $(p T)$.

Arus perpindahan materi dari beberapa sub-populasi dalam model ini secara skematis disajikan dalam Gambar 1 berikut.

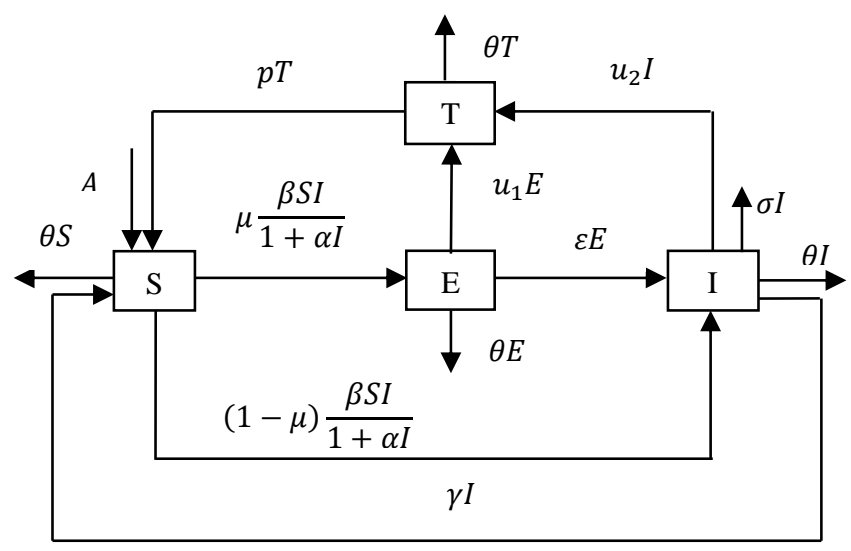

Gambar 1 Diagram laju perubahan populasi

Untuk selanjutnya $S(t), E(t), I(t), T(t)$ cukup ditulis dengan $S, E, I, T$ tanpa mengubah adanya variabel $t$ didalamnya, sehingga diperoleh laju perubahan sub-populasi susceptible, exposed, infective, dan treatment yang memenuhi sistem persamaan diferensial sebagai berikut.

\section{Dengan}

$$
\left.\begin{array}{l}
\dot{S}=A-\theta S-\frac{\beta S I}{1+\alpha I}+\gamma I+p T \\
\dot{E}=\mu \frac{\beta S I}{1+\alpha I}-\left(\theta+\varepsilon+u_{1}\right) E \\
\dot{I}=(1-\mu) \frac{\beta S I}{1+\alpha I}+\varepsilon E-\left(\theta+\gamma+\sigma+u_{2}\right) I \\
\dot{T}=u_{1} E+u_{2} I-(p+\theta) T
\end{array}\right\}
$$

$\dot{S} \quad$ : banyaknya individu susceptible tiap waktu,

$\dot{E} \quad$ : banyaknya individu exposed tiap waktu,

$\dot{I} \quad$ : banyaknya individu infective tiap waktu, 
$\dot{T} \quad$ : banyaknya individu treatment tiap waktu,

$S \quad$ : banyaknya individu susceptibleE: banyaknya individu exposed,

I : banyaknya individu infective,

$T$ : banyaknya individu treatment,

$A$ : banyaknya kelahiran alami,

$\theta \quad$ : tingkat kematian alami,

$\sigma \quad$ : tingkat kematian akibat penyakit,

$\gamma \quad$ : tingkat individu infective yang kembali susceptible,

$p \quad$ : tingkat individu treatment yang kembali susceptible,

$\varepsilon \quad$ : tingkat individu exposed yang menjadi infective,

$\mu \quad$ : tingkat individu infective yang menjadi exposed,

$1-\mu$ : tingkat individu yang infective yang menjadi infective,

$\beta \quad$ : tingkat transmisi,

$\frac{\beta S I}{1+\alpha I}:$ tingkat kejadian tersaturasi (saturated incidence rate),

$u_{1} \quad:$ kontrol pengobatan individu exposed,

$u_{2}$ : kontrol pengobatan individu infective,

dengan $0 \leq \mu \leq 1$, dan $A, \theta, \sigma, \gamma, p, \varepsilon, \beta>0$.

Misalkan $N(t)$ adalah populasi tiap waktu dengan $N=S-E-I-T$, maka laju perubahan populasi tiap waktu berdasarkan Persamaan (9) diperoleh

$$
\dot{N}=\dot{S}+\dot{E}+\dot{I}+\dot{T}=A-\theta N-\sigma I
$$

Berdasarkan Persamaan (10) dapat dikonstruksi sistem baru dari Persamaan (9), yaitu

$$
\left.\begin{array}{l}
\dot{E}=\mu \frac{\beta I}{1+\alpha I}(N-E-I-T)-\left(\theta+\varepsilon+u_{1}\right) E \\
\dot{I}=(1-\mu) \frac{\beta I}{1+\alpha I}(N-E-I-T)+\varepsilon E(t)-\left(\theta+\gamma+\sigma+u_{2}\right) I \\
\dot{T}=u_{1} E+u_{2} I-(p+\theta) T \\
\dot{N}=A-\theta N-\sigma I
\end{array}\right\}
$$

\section{Penyelesaian Kontrol Optimal}

Berdasarkan pinsip minimum Pontryagin langkah pertama yang harus dilakukan untuk memperoleh kontrol optimal adalah menentukan fungsi Hamiltonian. Fungsi Hamilton didapatkan berdasarkan Persamaan (4), yaitu dengan mensubstitusikan Persamaan (3) dan Persamaan (11) didapat

$$
\begin{aligned}
H=I+\frac{C}{2} u_{1}^{2}+ & \frac{D}{2} u_{2}^{2}+\lambda_{1}\left(\mu \frac{\beta I}{1+\alpha I}(N-E-I-T)-\left(\theta+\varepsilon+u_{1}\right) E\right) \\
& +\lambda_{2}\left((1-\mu) \frac{\beta I}{1+\alpha I}(N-E-I-T)+\varepsilon E(t)-\left(\theta+\gamma+\sigma+u_{2}\right) I\right) \\
& +\lambda_{3}\left(u_{1} E+u_{2} I-(p+\theta) T\right)+\lambda_{4}(A-\theta N-\sigma I)
\end{aligned}
$$

Menurut prinsip minimum Pontryagin, fungsi Hamiltonian mencapai solusi optimal jika berlaku persamaan state, costate, dan kondisi stasioner.

1) Persamaan state

$$
\begin{aligned}
& \dot{x}_{1}=\left(\frac{\partial H}{\partial \lambda_{1}}\right)=\mu \frac{\beta I}{1+\alpha I}(N-E-I-T)-\left(\theta+\varepsilon+u_{1}\right) E \\
& \dot{x}_{2}=\left(\frac{\partial H}{\partial \lambda_{2}}\right)=(1-\mu) \frac{\beta I}{1+\alpha I}(N-E-I-T)+\varepsilon E-\left(\theta+\gamma+u_{2}\right) I \\
& \dot{x}_{3}=\left(\frac{\partial H}{\partial \lambda_{3}}\right)=u_{1} E+u_{2} I-(p+\theta) T \\
& \dot{x}_{4}=\left(\frac{\partial H}{\partial \lambda_{4}}\right)=A-\theta N-\sigma I
\end{aligned}
$$


dengan kondisi awal yaitu $E(0)=E_{0}, I(0)=I_{0}, T(0)=T_{0}$, dan $N(0)=N_{0}$,

2) Persamaan costate

$$
\begin{aligned}
& \begin{aligned}
\dot{\lambda}_{1}=-\frac{\partial H}{\partial E}= & \frac{\left(\lambda_{1} \mu+\lambda_{2}(1-\mu)\right) \beta I}{1+\alpha I}+\left(\lambda_{1}-\lambda_{2}\right) \varepsilon+\left(\lambda_{1}-\lambda_{3}\right) u_{1}+\lambda_{1} \theta \\
\dot{\lambda}_{2}=-\frac{\partial H}{\partial I}= & -\left(\lambda_{1} \mu+\lambda_{2}(1-\mu)\right)\left(\frac{\beta\left(N-E-2 I-T-\alpha I^{2}\right)}{(1+\alpha I)^{2}}\right)+\lambda_{2}(\theta+\gamma)+\left(\lambda_{2}-\lambda_{3}\right) u_{2} \\
& +\left(\lambda_{2}+\lambda_{4}\right) \sigma-1
\end{aligned} \\
& \dot{\lambda}_{3}=-\frac{\partial H}{\partial T}=\frac{\left(\lambda_{1} \mu+\lambda_{2}(1-\mu)\right) \beta I}{1+\alpha I}+\lambda_{3}(p+\theta) \\
& \dot{\lambda}_{4}=-\frac{\partial H}{\partial N}=-\frac{\left(\lambda_{1} \mu+\lambda_{2}(1-\mu)\right) \beta I}{1+\alpha I}+\lambda_{4} \theta
\end{aligned}
$$

dengan kondisi batas yaitu $\lambda_{1}\left(t_{f}\right)=0, \lambda_{2}\left(t_{f}\right)=0, \lambda_{3}\left(t_{f}\right)=0$, dan $\lambda_{4}\left(t_{f}\right)=0$.

3) Kondisi stasioner

$$
\begin{aligned}
& {\frac{\partial H^{*}}{\partial u_{1}(t)}}^{*}=0 \\
& \frac{\partial H^{*}}{\partial u_{2}(t)}=0
\end{aligned}
$$

Sehingga diperoleh kondisi stasioner

$$
\begin{aligned}
& {\frac{\partial H^{*}}{\partial u_{1}(t)}}^{*}=C u_{1}(t)-\lambda_{1}(t) E(t)+\lambda_{3}(t) E(t) \\
& {\frac{\partial H}{\partial u_{2}(t)}}^{*}=D u_{2}(t)-\lambda_{2}(t) I(t)+\lambda_{3}(t) I(t)
\end{aligned}
$$

Selanjutnya dicari $u_{1}(t)$ dan $u_{2}(t)$ pada Persamaan (12) dan (13), didapat persamaan kontrol optimal sebagai berikut,

$$
\begin{aligned}
& \bar{u}_{1}(t)=\frac{E(t)\left(\lambda_{1}(t)-\lambda_{3}(t)\right)}{C} \\
& \bar{u}_{2}(t)=\frac{I(t)\left(\lambda_{2}(t)-\lambda_{3}(t)\right)}{D}
\end{aligned}
$$

Karena nilai kontrolnya terbatas, dimana $0 \leq u_{1}(t), u_{2}(t) \leq 0,9$ sehingga bentuk kontrol yang optimal adalah

$$
\begin{aligned}
& u_{1}^{*}(t)=\min \left(0,9 ; \operatorname{maks}\left(0, \bar{u}_{1}(t)\right)\right) \\
& u_{2}^{*}(t)=\min \left(0,9 ; \operatorname{maks}\left(0, \bar{u}_{2}(t)\right)\right)
\end{aligned}
$$

Untuk mendapatkan sistem yang optimal yaitu dengan memasukkan kontrol optimal $u_{1}^{*}(t)$ dan $u_{2}^{*}(t)$ ke sistem persamaan state dan costate yang telah diperoleh, sehingga didapatkan sistem optimal dengan kondisi awal dan kondisi batas berturut-turut yaitu $E(0)=E_{0}, I(0)=I_{0}, T(0)=T_{0}, N(0)=N_{0}$, $\lambda_{1}\left(t_{f}\right)=0, \lambda_{2}\left(t_{f}\right)=0, \lambda_{3}\left(t_{f}\right)=0, \lambda_{4}\left(t_{f}\right)=0$.

\section{Simulasi Numerik}

Pada pembahasan berikutnya, akan dilakukan simulasi dan analisis hasil simulasi dengan menggunakan nilai parameter pada Tabel 1 dan menggunakan nilai awal atau populasi awal $\left(S_{0}, E_{0}, I_{0}, T_{0}, N_{0}\right)=$ $(400,15,20,0,435)$. Simulasi yang dilakukan meliputi simulasi sub-populasi Susceptible, subpopulasi individu Exposed, sub-populasi Infective, sub-populasi Treatment, total populasi $(N)$, kontrol $u_{1}$, kontrol $u_{2}$, dan fungsi objektif $J\left(u_{1}, u_{2}\right)$. 
Tabel 1 Nilai parameter yang digunakan dalam simulasi

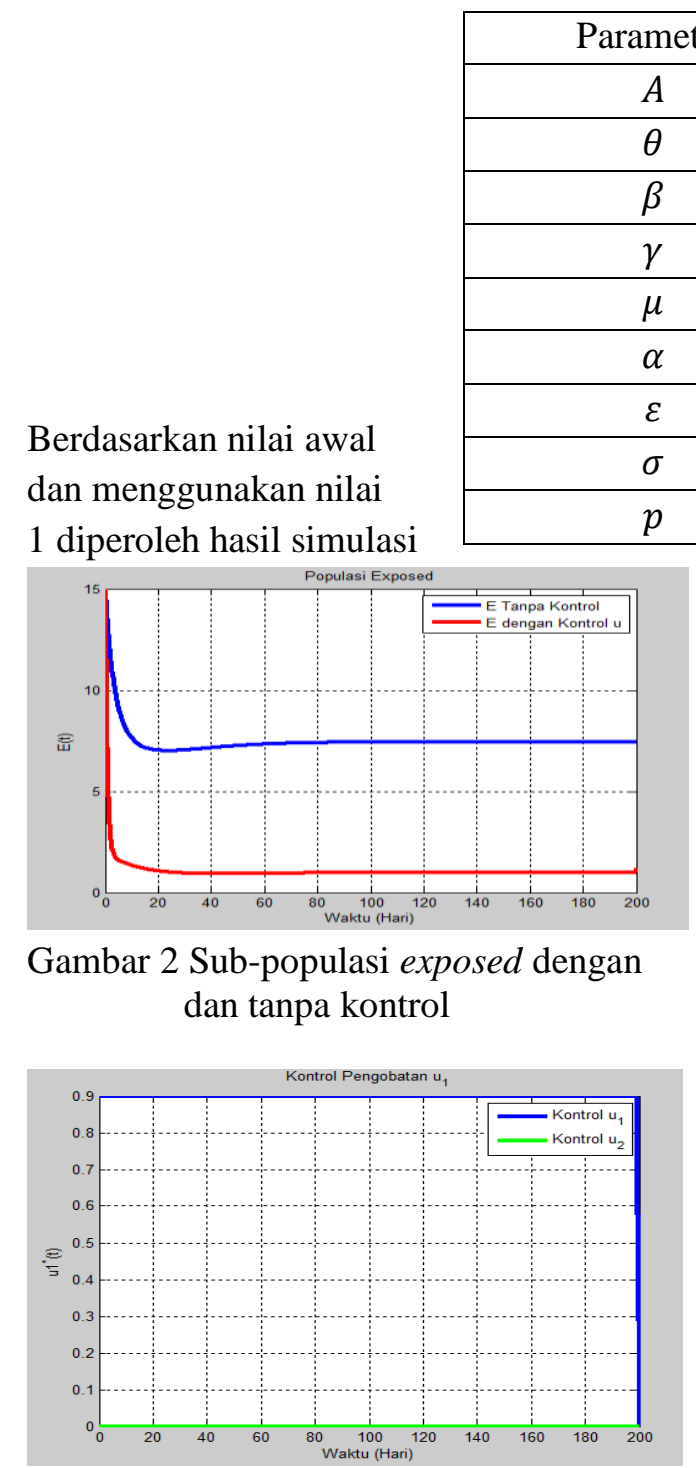

Gambar 4 Kontrol $u_{1}$ dan $u_{2}$

Gambar 2 Sub-populasi exposed dengan atau populasi awal parameter pada Tabel sebagai berikut, dan tanpa kontrol

Gambar 2 adalah perbandingan perubahan jumlah individu exposed tanpa dan dengan kontrol. Berdasarkan Gambar tersebut menunjukkan bahwa dengan adanya kontrol pengobatan lebih efektif menurunkan jumlah individu exposed dibandingkan dengan tanpa kontrol. Individu tanpa kontrol mengalami penurunan dari awal periode hingga mencapai konstan pada waktu ke-83 yaitu sebesar 7 individu, sedangkan individu dengan kontrol mengalami penurunan dari awal periode hingga mencapai konstan pada hari ke-76 yaitu sebesar 1 individu.

Gambar 3 adalah perbandingan perubahan jumlah individu infective tanpa dan dengan kontrol. Berdasarkan Gambar tersebut menunjukkan bahwa dengan adanya kontrol pengobatan lebih efektif menurunkan jumlah individu infective dibandingkan dengan tanpa kontrol. Individu tanpa kontrol mengalami penurunan dari awal periode hingga mencapai konstan pada waktu ke-110 yaitu sebesar 11 individu, sedangkan individu dengan kontrol mengalami penurunan dari awal periode hingga mencapai konstan pada hari ke-115 yaitu sebesar 3 individu.

Gambar 4 adalah pemberian kontrol $u_{1}$ dan $u_{2}$. Gambar tersebut menunjukkan bahwa pemberian kontrol $u_{1}$ pada awal periode pemberian pengobatan adalah maksimum yaitu sebesar 0.9 sampai hari 
ke-198, kemudian mulai mengalami penurunan sampai 0 pada akhir periode. Sedangkan pemberian kontrol $u_{2}$ sejak hari pertama hingga akhir periode bernilai konstan yaitu 0 .

Gambar 5 adalah gambar grafik fungsi objektif. Berdasarkan gambar tersebut tampak bahwa dengan adanya kontrol $u_{1}$ dan $u_{2}$ dapat meminimumkan fungsi objektif

\section{KESIMPULAN}

Berdasarkan tujuan penelitian yang telah dilakukan dapat ditarik kesimpulan sebagai berikut.

1. Model epidemi tipe SEIT dengan pemberian kontrol pengobatan $u_{1}$ pada individu exposed dan $u_{2}$ pada individu infective yang dilakukan secara bersamaan adalah

$$
\begin{aligned}
& \dot{S}(t)=A-\theta S(t)-\frac{\beta S(t) I(t)}{1+\alpha I(t)}+\gamma I(t)+p T(t) \\
& \dot{E}(t)=\mu \frac{\beta S(t) I(t)}{1+\alpha I(t)}-\left(\theta+\varepsilon+u_{1}\right) E(t) \\
& \dot{I}(t)=(1-\mu) \frac{\beta S(t) I(t)}{1+\alpha I(t)}+\varepsilon E(t)-\left(\theta+\gamma+\sigma+u_{2}\right) I(t) \\
& \dot{T}(t)=u_{1} E(t)+u_{2} I(t)-(p+\theta) T(t)
\end{aligned}
$$

2. Berdasarkan hasil analisis, kontrol pengobatan pada model dengan menerapkan metode Prinsip Minimum Pontryagin diperoleh kontrol dan sistem yang optimal.

3. Simulasi numerik yang dilakukan menunjukkan hasil yang sesuai dengan hasil analisis. Hasil simulasi menunjukkan keefektifan kontrol dalam mengendalikan penyebaran suatu penyakit sehingga dapat mengurangi jumlah individu infective dan meminimumkan biaya pengobatan.

\section{DAFTAR PUSTAKA}

[1] Setiawan. Kontrol Optimal Penyebaran Tuberkulosis dengan Exogenous Reinfection [tesis]. Depok: Fakultas MIPA Universitas Indonesia; 2012.

[2] Fathoni MIA. Analisis Sistem Dinamik dan Kontrol Optimal pada Model Epidemi Tipe SEIT dengan Perbedaan Periode Exposed dengan Kejadian Tersaturasi [tesis]. Surabaya: Fakultas MIPA Institut Teknologi Sepuluh Nopember; 2015.

[3] Copasso V dan Serio G. A Generalization of the Kermack-McKendrick Deterministic Epidemic Model. Mathematical Biosciences. 1978; 42:43-61.

[4] Zhang J, Jia J, dan Song X. Analysis of an SEIR Epidemic Model with Saturated Incidence and Saturated Treatment Function. The Scientific Word Journal. 2014.

[5] Naidu DS. Optimal Control System, USA: CRC Presses LCC; 2012.

[6] Hia ME, Balatif O, Bouyaghroumni J, Labriji E dan Rachik M. Optimal Control Applied to the Spread of Influenza A(H1N1). Applied Mathematical Sciences. 2012; 6:4057-4065.

$\begin{array}{ll}\text { LAILA TUL MACHFIROH } & : \text { Universitas Tanjungpura, Jl. Prof. Dr. H. Hadari Nawawi } \\ & \text { lailatul.maghfiroh111@ gmail.com } \\ \text { HELMI } & \text { Universitas Tanjungpura, Jl. Prof. Dr. H. Hadari Nawawi } \\ & \text { helmi132205@ yahoo.ac.id } \\ & : \text { Universitas Tanjungpura, Jl. Prof. Dr. H. Hadari Nawawi } \\ & \text { yudhi@ math.untan.ac.id }\end{array}$

